\title{
Use of inflammatory molecules to predict the occurrence of fever in onco-hematological patients with neutropenia
}

\author{
A.F. Tibúrcio Ribeiro ${ }^{1}$, V. Nobre ${ }^{1}$, L.C. Neuenschwander ${ }^{1}$, A.L. Teixeira ${ }^{2}$, S.G. Xavier ${ }^{3}$ \\ F.D.F. Paula ${ }^{3}$, M.M. Teixeira ${ }^{2}$, J.C.A. Teixeira ${ }^{1}$ and H. Bittencourt ${ }^{1}$ \\ ${ }^{1}$ Departamento de Clínica Médica, Faculdade de Medicina, Universidade Federal de Minas Gerais, Belo Horizonte, MG, Brasil \\ ${ }^{2}$ Laboratório de Imunofarmacologia, Instituto de Ciências Biológicas, Universidade Federal de Minas Gerais, \\ Belo Horizonte, MG, Brasil \\ ${ }^{3}$ Departamento de Propedêutica, Faculdade de Medicina, Universidade Federal de Minas Gerais, Belo Horizonte, MG, Brasil
}

\begin{abstract}
Febrile neutropenia remains a frequent complication in onco-hematological patients, and changes in the circulating level of inflammatory molecules (IM) may precede the occurrence of fever. The present observational prospective study was carried out to evaluate the behavior of plasma tumor necrosis factor alpha (TNF- $\alpha$ ), soluble TNF- $\alpha$ I and II receptors (sTNFRI and STNFRII), monocyte chemoattractant protein-1 [MCP-1 or chemokine (c-c motif) ligand 2 (CCL2)], macrophage inflammatory protein-1 $\alpha$ (MIP-1 $\alpha$ or CCL3), eotaxin (CCL11), interleukin-8 (IL-8 or CXCL8), and interferon-inducible protein-10 (IP-10 or $\mathrm{CXCL} 10$ ) in 32 episodes of neutropenia in 26 onco-hematological patients. IM were tested on enrollment and $24-48 \mathrm{~h}$ before the onset of fever and within $24 \mathrm{~h}$ of the first occurrence of fever. Eight of 32 episodes of neutropenia did not present fever (control group) and the patients underwent IM tests on three different occasions. STNFRI levels, measured a median of $11 \mathrm{~h}(1-$ $15)$ before the onset of fever, were significantly higher in patients presenting fever during follow-up compared to controls $(P=$ 0.02). Similar results were observed for sTNFRI and CCL2 levels $(P=0.04$ for both) in non-transplanted patients. A cut-off of $1514 \mathrm{pg} / \mathrm{mL}$ for sTNFRI was able to discriminate between neutropenic patients with or without fever during follow-up, with $65 \%$ sensitivity, $87 \%$ specificity, and $93 \%$ positive predictive value. Measurement of the levels of plasma sTNFRI can be used to predict the occurrence of fever in neutropenic patients.
\end{abstract}

Key words: Neutropenia; Cytokines; Oncological hematology

\section{Introduction}

A significant improvement in the outcome of patients with hematological malignancies has been observed, mainly due to progress in treatment and supportive care $(1,2)$. In spite of the indisputable advance in the management of these patients, many clinical challenges remain, such as opportunistic infections, drug toxicity, and hemorrhages $(3,4)$.

Infectious complications related to neutropenia are the leading cause of morbidity and mortality in onco-hematological patients. Neutropenia is classically defined as a neutrophil count below $0.5 \times 10^{9} / \mathrm{L}$ (5). Management of infections in neutropenic patients is especially challenging owing to their nonspecific signs and symptoms. Fever is regarded as an early warning sign in patients with neutropenia, and all guidelines recommend prompt use of broad-spectrum antibiotic therapy when it occurs (5-7).
However, fever might not be a sufficiently precocious marker of infection in neutropenic patients, leading to an undesirable delay in the use of antibiotic therapy. In addition, some patients do not present fever at all despite severe bacterial or fungal infections (8-11).

Cytokines and other inflammatory molecules have the ability to promote the onset of fever, to recruit different immune system cells to the site of infection, and to act on hematopoiesis and cell regulation (12). It appears that a change in plasma levels of some of these molecules precedes the occurrence of fever in neutropenic patients. Therefore, the aim of this study was to evaluate the ability of using the levels of eight different inflammatory molecules to predict the occurrence of fever in a population of onco-hematological neutropenic patients.

Correspondence (current address): H. Bittencourt, Hematology-Oncology Service, C.H.U. Sainte-Justine, 3175 Ch Cote-SainteChaterine, Montreal, Qc, H3T 1C5, Canada. E-mail: hn.bittencourt@umontreal.ca 


\section{Material and Methods}

This was a prospective observational pilot study with onco-hematological patients admitted to a 400-bed University Hospital in Southeast Brazil, a regional reference hospital for the management of patients with hematological diseases and hematopoietic stem cell transplantation (HSCT). The study protocol was approved by the Ethics Review Board of Universidade Federal de Minas Gerais (Process. No. 0250.0.203.000-08), and written informed consent was obtained from all patients or their legal representative.

All consecutive adult ( $\geqslant 18$ years) patients, hospitalized from September 2008 to March 2009 and presenting neutropenia (defined as a neutrophil count $<1.0 \times 10^{9} / \mathrm{L}$ ) were assessed for eligibility. Inclusion criteria were as follows: 1) to be afebrile for at least $48 \mathrm{~h}$ before enrollment; 2) to present no sign/symptom of clinically and/or radiologically active infection for at least $48 \mathrm{~h}$ before enrollment; 3 ) to be diagnosed with a malignant hematological disorder or severe aplastic anemia, and 4) to present neutropenia expected to last for at least 6 days. Fever was defined as a single axillary temperature $\geqslant 38.3^{\circ} \mathrm{C}$ or axillary temperature $\geqslant 37.8^{\circ} \mathrm{C}$ sustained for at least $1 \mathrm{~h}$. Inclusion of more than one neutropenia episode per patient was allowed, provided it occurred in different hospitalizations and that neutropenia receded between hospitalizations. Patients receiving therapeutic antibiotics and/or with hospital discharge planned for the next 5 days were not included in the study.

Clinical evaluation and full medical history were obtained for all participants. Clinical data were recorded at baseline and during follow-up. Routine blood tests were recorded at inclusion and periodically thereafter, along with results from microbiologic cultures. In 10 HSCT patients, data on the type of transplant, HLA compatibility and graft source were also recorded. Axillary temperature was routinely measured every $4 \mathrm{~h}$ during hospitalization. Patients were followed for 28 days, or until the first episode of fever, death or discharge, whichever came first. Patients were divided into two groups: group 1, all patients presenting fever during the follow-up period, and group 2 (control group), patients that did not present fever during follow-up. All diagnostic and therapeutic interventions were performed by the attending physician as clinically indicated.

\section{Laboratory tests}

To measure plasma levels of different inflammatory molecules, peripheral blood samples were collected daily (early in the morning), using EDTA tubes (BD Vacutainer; Becton Dickinson Diagnostic Systems, Brazil). Blood samples were centrifuged and the resulting plasma was frozen and stored at $-80^{\circ} \mathrm{C}$. The following inflammatory molecules were tested: plasma tumor necrosis factor alpha (TNF- $\alpha$ ), soluble TNF- $\alpha$ I and II receptors (sTNFRI and STNFRII, respectively), monocyte chemotactic protein-1 (MCP-1/CCL2), macrophage inflammatory protein $1 \alpha$ (MIP-1 $\alpha /$ CCL3), eotaxin (CCL11), interleukin 8 (IL-8/ CXCL8), and interferon gamma-induced protein (IP-10/ CXCL10). Plasma was thawed at room temperature in order to determine the circulating levels of each molecule using a sandwich-type ELISA method (Duoset, R \& D Systems, USA) according to manufacturer instructions. The detection limit of the ELISA was approximately $5 \mathrm{pg} /$ $\mathrm{mL}$ for all inflammatory molecules. Inter- and intra-assay coefficients of variation were below $10 \%$ and all assays were performed in duplicate.

Plasma levels of inflammatory molecules were analyzed at three different times in group 1 patients: on enrollment (T0); 48 to $24 \mathrm{~h}$ before the first onset of fever (T1), and within $24 \mathrm{~h}$ of the first occurrence of fever (T2). Final blood samples for each febrile patient were collected at a median time of $11 \mathrm{~h}$ (range: 1-15 h) before the onset of fever. Given the absence of fever as a benchmark, arbitrary points were defined to test inflammatory markers among group 2 (control group) subjects. Three time points were chosen according to neutropenia duration, as follows: upon inclusion (T0), at the median (T1), and on the final (T2) day of the neutropenia period, for each patient.

\section{Statistical analysis}

The primary end point was the occurrence of fever during neutropenia. We tested whether a difference in plasma levels of different inflammatory molecules among neutropenic patients predicted the occurrence of fever during the follow-up period. A subgroup analysis was performed including non-transplanted patients only. Discrete variables are reported as percentages, and continuous variables as median and range. Differences between groups were tested by the chi-square or the Fisher exact test for categorical variables, and the MannWhitney U-test was used for continuous variables. Results are presented as crude (unadjusted) data with $95 \%$ confidence intervals. The diagnostic accuracy of each inflammatory plasma level presenting statistical significance was expressed as the area under the receiver operating characteristic curve (ROC), from which the best cut-offs and their related sensitivity, specificity, positive (PPV) and negative (NPV) predictive values were calculated. Statistical analysis was performed using the SPSS 12.0 software (Chicago University, USA). Significance was reported at a $\mathrm{P}$ value of 0.05 or less.

\section{Results}

A total of 211 episodes of neutropenia were assessed for eligibility, 41 episodes that occurred in 33 patients fulfilled the required criteria. Most neutropenia episodes were not considered to be eligible for this study because they did not fulfill the criteria for neutropenia duration (in 
Table 1. Clinical characteristics of neutropenic patients presenting fever or not.

\begin{tabular}{lccc}
\hline & All patients & Patients with fever episode & Patients without fever episode \\
\hline Numbers of patients & $26^{*+}$ & $20^{+}$ & $8^{+}$ \\
Male gender & $19(73 \%)$ & $15(75 \%)$ & $6(75 \%)$ \\
Age (years) & $36(18-69)$ & $35(20-64)$ & $36(18-69)$ \\
Diagnosis & & & $3(37.5 \%)$ \\
Acute myeloid leukemia & $9(35 \%)$ & $7(35 \%)$ & - \\
Multiple myeloma & $4(15 \%)$ & $4(20 \%)$ & $1(12.5 \%)$ \\
Myelodysplastic syndrome & $3(11 \%)$ & $2(10 \%)$ & $3(37.5 \%)$ \\
Non-Hodgkin lymphoma & $6(23 \%)$ & $4(20 \%)$ & - \\
Hodgkin lymphoma & $2(8 \%)$ & $2(10 \%)$ & - \\
Aplastic anemia & $1(4 \%)$ & $1(5 \%)$ & 0 \\
Acute lymphocytic leukemia & $1(4 \%)$ & $12.5 \%)$ \\
\hline
\end{tabular}

Data are reported as number (\%) or median (range). *Two patients were included twice: once in the febrile group and once in the afebrile group for one patient and twice in febrile group for another. Two patients were included three times: twice in the febrile group and once in the afebrile group for one patient and three times in the febrile group for another. 'Two patients were included in both groups.

most cases, short-term neutropenia in lymphoma, myeloma or solid tumor patients) and/or patients had already presented fever before inclusion. A further 9 of the 41 episodes were additionally excluded because a final plasma sample (T2) before fever was unavailable. Therefore, 32 episodes of neutropenia, observed in 26 patients, were included in the final analysis. The clinical characteristics of the patients included are summarized in Table 1.

As expected, all patients were neutropenic on inclusion, and median neutrophil count was $0.27(0-0.99) 10^{9} /$ L. Median follow-up time was 3 (1-27) days. Twenty-four (75\%) episodes of neutropenia developed fever during the follow-up period. Median time from enrollment to fever was 2 days (range 1-9 days). Blood samples for cultures were collected for 23 of 24 episodes of fever and 7 (29\%) cultures were positive. There was no episode of fever related to drug infusion or blood transfusion. As shown in
Table 1, there were no differences in the clinical characteristics of patients presenting fever, or not, during follow-up.

\section{Dynamic behavior of the different plasma markers}

Circulating levels of the tested inflammatory molecules measured at three different times for the whole study population are summarized in Table 2. Significantly higher levels of STNFRI were observed in the final sample before fever (within $24 \mathrm{~h}$ of fever) in group 1 compared to the levels measured on the corresponding neutropenia (T2) day in the control group $(P=0.029$; Table 3 and Figure 1). No difference was observed for the remaining molecules.

In order to define the ability of plasma sTNFRI levels to be used to identify neutropenic patients who are at risk of presenting fever, an ROC curve was constructed and a cut-off value of $1514 \mathrm{pg} / \mathrm{mL}$ was identified as showing the

Table 2. Median plasma levels of inflammatory molecules measured at different times in the entire population of neutropenic patients.

\begin{tabular}{lccc}
\hline Inflammatory molecules & T0 $(\mathrm{n}=19)$ & $\mathrm{T} 1(\mathrm{n}=22)$ & $\mathrm{T} 2(\mathrm{n}=31)$ \\
\hline TNF- $\alpha$ & $110.03(0-799.82)$ & $158.8(0-730.79)$ & $95.74(0-720.31)$ \\
STNFRI & $1261.6(647.26-2381.56)$ & $1316.8(647.26-4593.31)$ & $1557.26(731.37-6306.12)$ \\
STNFRII & $2498.31(1441.34-4036.09)$ & $2610.4(1510.03-4953.69)$ & $2915.10(1514.7-5546.53)$ \\
CXCL8 & $104.23(33.21-223.85)$ & $118.5(48.05-631.21)$ & $130.21(13.49-1070.16)$ \\
CCL3 & $48.9(5-1071.95)$ & $107.7(18-1068.14)$ & $75.58(5-1031.50)$ \\
CCL11 & $203.90(95.12-659.98)$ & $189.1(115.66-524.82)$ & $164.89(121.75-601.00)$ \\
CXCL10 & $0.00(0-641.74)$ & $0.00(0-650.60)$ & $12.27(0-269.35)$ \\
CCL2 & $1834.4(0-6492.26)$ & $1460.4(0-3535.94)$ & $1384.01(0-6278.90)$ \\
\hline
\end{tabular}

Data are reported in $\mathrm{pg} / \mathrm{mL}$ as median (range). T0 $=$ on inclusion; $\mathrm{T} 1=48$ to $24 \mathrm{~h}$ before the first occurrence of fever; T2 $=$ within $24 \mathrm{~h}$ of the first occurrence of fever. TNF- $\alpha=$ tumor necrosis factor- $\alpha$; sTNFRI $=$ soluble TNF- $\alpha$ I receptor; sTNFRII $=$ soluble TNF- $\alpha$ II receptor; CXCL8 = interleukin-8; CCL3 = macrophage inflammatory protein-1 $\alpha$; CCL11 = eotaxin; CXCL10 = interferon-inducible protein-10; CCL2 = chemokine (c-c motif) ligand 2 . 
Table 3. Dynamic behavior of the different plasma inflammatory molecule levels in the entire population of neutropenic patients with fever or not.

\begin{tabular}{|c|c|c|c|c|c|c|}
\hline \multirow[t]{2}{*}{ Inflammatory molecules } & \multicolumn{2}{|c|}{ TO } & \multicolumn{2}{|c|}{$\mathrm{T} 1$} & \multicolumn{2}{|c|}{$\mathrm{T} 2$} \\
\hline & $\begin{array}{c}\text { Fever } \\
(\mathrm{n}=8)\end{array}$ & $\begin{array}{l}\text { No fever } \\
(\mathrm{n}=11)\end{array}$ & $\begin{array}{c}\text { Fever } \\
(\mathrm{n}=7)\end{array}$ & $\begin{array}{l}\text { No fever } \\
(n=15)\end{array}$ & $\begin{array}{c}\text { Fever } \\
(\mathrm{n}=8)\end{array}$ & $\begin{array}{l}\text { No fever } \\
(n=23)\end{array}$ \\
\hline TNF- $\alpha$ & 110.0 & 94.9 & 177.1 & 53.1 & 127.8 & 88.8 \\
\hline sTNFRI & 1261.6 & 1241.4 & 1356.4 & 1089.1 & $1877.8^{*}$ & 1290.4 \\
\hline sTNFRII & 2498.3 & 2567.0 & 2785.0 & 2599.6 & 3190.5 & 2657.2 \\
\hline CXCL8 & $77.6^{*}$ & 150.9 & 108.9 & 143.3 & 139.0 & 120.9 \\
\hline CCL3 & 30.3 & 70.5 & 107.5 & 125.0 & 83.6 & 49.5 \\
\hline CCL11 & 208.4 & 184.4 & 168.8 & 191.8 & 162.8 & 177.7 \\
\hline CXCL10 & 0.0 & 0.0 & 0.0 & 0.0 & 16.8 & 12.2 \\
\hline CCL2 & 1834.4 & 1625.9 & 1384.0 & 2189.8 & 1812.9 & 858.1 \\
\hline
\end{tabular}

Data are reported in $\mathrm{pg} / \mathrm{mL}$ as median. T0 $=$ on inclusion; T1 $=48$ to $24 \mathrm{~h}$ before the first occurrence of fever; T2 = within $24 \mathrm{~h}$ of the first occurrence of fever. For abbreviations, see legend to Table 2. ${ }^{*} \mathrm{P}<0.05$ compared to patients with no fever (Mann-Whitney U-test).

best discrimination between neutropenic patients presenting fever, or not, within $24 \mathrm{~h}$, with $65 \%$ sensitivity, $87 \%$ specificity, 93\% PPV, $46 \%$ NPV, and $70 \%$ accuracy.

Since about one third of our patients presented neutropenia after HSCT, a subgroup analysis was performed including only episodes in non-transplanted patients $(\mathrm{N}=22)$. In this case, significantly higher plasma levels of STNFRI and CCL2 were observed in the final sample before fever (within $24 \mathrm{~h}$ of fever) for patients in group 1 compared to control ( $P=0.04$ for both; Table 4). ROC curve analysis was also performed to evaluate the best cut-off value in this subgroup. Similar to the overall population, the best cut-off of sTNFRI for predicting the occurrence of fever among non-transplanted neutropenic

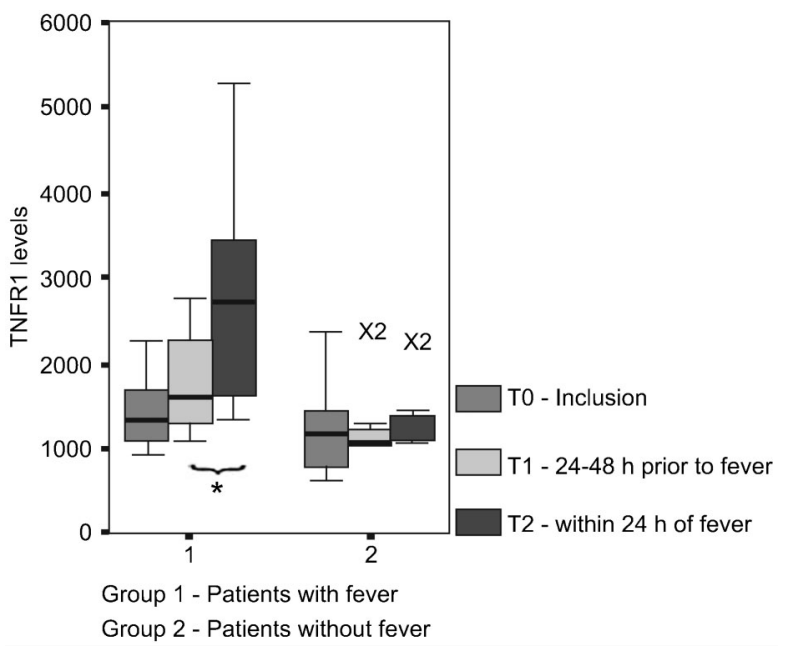

Figure 1. Plasma levels of soluble TNF- $\alpha$ | receptor (TNFRI) measured at enrollment, 24 to $48 \mathrm{~h}$ before the occurrence of fever, and within 24 h of fever onset (group 1) compared to the corresponding days in the group without fever (group 2). X2 = outliers. ${ }^{*} \mathrm{P}<0.05$ compared to group 2 (Mann-Whitney U-test). patients was $1514 \mathrm{pg} / \mathrm{mL}$, with $71 \%$ sensitivity, $87 \%$ specificity, 91\% PPV, 63\% NPV, and 77\% accuracy. CCL2 did not present a satisfactory discriminatory performance, with an accuracy of less than $50 \%$.

\section{Discussion}

This exploratory study whose objective was to use the levels of circulating inflammatory molecules to predict the occurrence of fever in onco-hematological patients with chemotherapy-induced or disease-related neutropenia. We showed that, among the individuals studied, a significant elevation in circulating levels of sTNFRI preceded the onset of fever, with a median interval of $11 \mathrm{~h}$. Similar results were observed in a subgroup of nontransplanted patients. A cut-off of $1514 \mathrm{pg} / \mathrm{mL}$ was shown to be the best discriminative value for STNFRI in order to identify neutropenic patients who would present fever.

Fever is the main, and frequently the only, clinical sign used to guide antibiotic treatment in neutropenic patients. However, fever may also be a delayed sign, or even not occur at all, despite the presence of a life-threatening infection. Early use of antibiotic therapy was demonstrated to have improved outcome in different clinical scenarios (13-15). It is conceivable that a test that precociously detects the presence of infection, onset of fever and other clinical signs, could improve the outcome of neutropenic individuals (16). If so, the potential benefit of such a marker would be directly proportional to its accuracy and precocity.

Several biomarkers have been investigated for their utility in rapidly discriminating true infection from other inflammatory processes causing fever and two in particular, procalcitonin (17-20) and endotoxin (21,22), demonstrated their utility as an adjunctive diagnostic tool for discriminating severe bacterial infection in different clinical situations (i.e., sepsis, septic shock, and different 
Table 4. Dynamic behavior of the different plasma inflammatory molecule levels in neutropenic patients not undergoing transplantation with fever or not.

\begin{tabular}{|c|c|c|c|c|c|c|}
\hline \multirow[t]{2}{*}{ Inflammatory molecules } & \multicolumn{2}{|c|}{ T0 } & \multicolumn{2}{|c|}{$\mathrm{T} 1$} & \multicolumn{2}{|c|}{$\mathrm{T} 2$} \\
\hline & $\begin{array}{c}\text { Fever } \\
(n=8)\end{array}$ & $\begin{array}{l}\text { No fever } \\
(\mathrm{n}=7)\end{array}$ & $\begin{array}{c}\text { Fever } \\
(n=7)\end{array}$ & $\begin{array}{l}\text { No fever } \\
(n=11)\end{array}$ & $\begin{array}{c}\text { Fever } \\
(n=8)\end{array}$ & $\begin{array}{l}\text { No fever } \\
(n=14)\end{array}$ \\
\hline TNF- $\alpha$ & 164.1 & 94.9 & 207.6 & 53.1 & 212.4 & 88.8 \\
\hline sTNFRI & 1419.7 & 1241.4 & 1367.2 & 1089.1 & $1858.7^{*}$ & 1290.4 \\
\hline sTNFRII & 2679.9 & 2567.0 & 2785.0 & 2599.6 & 3283.9 & 2657.2 \\
\hline CXCL8 & 100.3 & 150.9 & 108.9* & 143.3 & 128.5 & 120.9 \\
\hline CCL3 & 78.9 & 70.5 & 107.9 & 125.0 & 100.0 & 49.5 \\
\hline CCL11 & 202.9 & 184.4 & 144.9 & 191.8 & 151.5 & 177.7 \\
\hline CXCL10 & 0.0 & 0.0 & 0.0 & 0.0 & 18.0 & 12.2 \\
\hline CCL2 & 2025.8 & 1625.9 & 1384.0 & 2189.8 & $2452.1^{*}$ & 858.1 \\
\hline
\end{tabular}

Data are reported in $\mathrm{pg} / \mathrm{mL}$ as median. T0 = on inclusion; T1 = 48 to $24 \mathrm{~h}$ before the first occurrence of fever; $\mathrm{T} 2=\mathrm{within} 24 \mathrm{~h}$ of the first occurrence of fever. For abbreviations, see legend to Table 2. ${ }^{*} \mathrm{P}<0.05$ compared to patients with no fever (Mann-Whitney U-test).

kinds of bacterial infections). A large number of publications have also addressed the usefulness of inflammatory molecules to predict the outcome of febrile neutropenia episodes (23-25). However, very few studies have tested the ability of circulating inflammatory molecules to predict (or anticipate) the occurrence of fever in this population (11,26-29). Engel et al. (11) evaluated the ability of serum levels of CXCL8, IL-6 and C-reactive protein (CRP) to predict the occurrence of fever in oncology patients with neutropenia. The levels of none of the tested cytokines was able to anticipate fever $24 \mathrm{~h}$ before its onset. The same group evaluated the circulating levels of procalcitonin and CXCL8 in patients with febrile neutropenia, correlating them with the occurrence of infection. Median procalcitonin levels increased from $0.16 \mathrm{ng} / \mathrm{mL}$, on the day before, to $0.34 \mathrm{ng} / \mathrm{mL}$, on the day after fever (27). Goetz et al. (28) tested the utility of sTNFRII in 54 patients with acute myeloid leukemia to provide an early diagnosis of sepsis during neutropenia. Eleven patients did not develop a fever. Median circulating levels of sTNFRII, tested on the day before fever, and on the day of fever, were similar (28). Finally, Buyukberber et al. (29) analyzed the soluble receptor levels of IL-2 (sIL-2R), IL-6, CXCL8, CRP, IL-1b, and TNF- $\alpha$ in 22 patients with oncohematological diseases before chemotherapy, and at different moments after treatment. No cytokine was found to be predictive of fever (29). These studies have dissimilarities in many key aspects, such as target population, tested molecules, sample size, study design, and blood sampling schedules. This heterogeneity may explain the different results and their inability to identify an inflammatory molecule able to predict fever in neutropenic individuals.

To be helpful to neutropenic patients, a feverpredictive tool must present elevated PPV, since a potential advantage of this test is to anticipate the commencement of antimicrobial therapy. Should fever occur, antibiotics would be prescribed regardless of the level of an inflammatory marker. In this study, the PPV for sTNFRI cut-off in the entire population and in the subgroup of non-transplanted patients was higher than $90 \%$.

Several limitations of this study must be mentioned. Firstly, most episodes of neutropenia assessed for eligibility were eventually not included in the study. As stated before, the main reason for exclusion was noncompliance with the criteria for duration of neutropenia and/or already having presented fever at assessment. In this study, we were particularly interested in a subgroup of long-duration neutropenia, usually considered to represent high-risk patients due to a higher risk of complication, even with antibiotic treatment. A selection bias, however, cannot be ruled out. Secondly, a small sample of patients was studied, which limited our statistical inferences. As noted, this was a pilot study designed to identify promising inflammatory markers to be studied in a large series of neutropenic patients. Thirdly, 10 patients underwent HSCT, and all of them presented fever at some point during neutropenia. It is well known that host tissues are directly damaged by conditioning chemotherapy used in transplants, or by different cytokines released after conditioning (IL-6, IL-1, TNF- $\alpha$, etc.), the so-called "cytokine storm" (30). This particular cytokine profile, which occurs early after HSCT, could limit the use of some inflammatory molecules as predictors of neutropenic fever. In fact, sTNFRI seems to be a better predictor for fever in non-transplanted patients. Unfortunately, the number of transplanted patients became too small to be analyzed as a subgroup. Finally, fever might also be due to reasons other than infection during neutropenia. To minimize this problem, only patients for whom fever was a determining factor in the use of antibiotic therapy by the attending physician were included in the study.

To the best of our knowledge, this is the first study to 
have evaluated sTNFRI, CCL2, CCL11, and CXCL10 in the context of neutropenia. Elevation of sTNFRI levels observed before fever has a biological background. TNF- $\alpha$ is a key inflammatory mediator in bacterial sepsis. It appears early following the event, initiating host response mechanisms, such as induction of other cytokines and fever (31-33). Virtually all cell types possess either sTNFRI or sTNFRII, or both, which mediate the vast range of the TNF- $\alpha$ effect. As TNF- $\alpha$ exerts its proinflammatory effect via two distinct cell surface receptors, on TNF- $\alpha$ stimulation, the extracellular domain of sTNFR can be shed into the blood (34-36). sTNFR can be measured earlier in serum than TNF- $\alpha$

\section{References}

1. Sanz MA, Grimwade D, Tallman MS, Lowenberg B, Fenaux $P$, Estey $E H$, et al. Management of acute promyelocytic leukemia: recommendations from an expert panel on behalf of the European LeukemiaNet. Blood 2009; 113: 18751891, doi: 10.1182/blood-2008-04-150250.

2. Blade J, Rosinol L, Cibeira MT, Rovira M, Carreras E. Hematopoietic stem cell transplantation for multiple myeloma beyond 2010. Blood 2010; 115: 3655-3663, doi: 10.1182/blood-2009-08-238196.

3. Rizzo JD, Somerfield MR, Hagerty KL, Seidenfeld J, Bohlius $\mathrm{J}$, Bennett $\mathrm{CL}$, et al. Use of epoetin and darbepoetin in patients with cancer: 2007 American Society of Hematology/American Society of Clinical Oncology clinical practice guideline update. Blood 2008; 111: 25-41, doi: 10.1182/blood-2007-08-109488.

4. Cornely OA, Bohme A, Buchheidt D, Glasmacher A, Kahl C, Karthaus $M$, et al. Prophylaxis of invasive fungal infections in patients with hematological malignancies and solid tumors - guidelines of the Infectious Diseases Working Party (AGIHO) of the German Society of Hematology and Oncology (DGHO). Ann Hematol 2003; 82 (Suppl 2): S186S200, doi: 10.1007/s00277-003-0773-3.

5. Freifeld AG, Bow EJ, Sepkowitz KA, Boeckh MJ, Ito JI, Mullen CA, et al. Clinical practice guideline for the use of antimicrobial agents in neutropenic patients with cancer: 2010 Update by the Infectious Diseases Society of America. Clin Infect Dis 2011; 52: 427-431, doi: 10.1093/cid/ciq147.

6. Sharma A, Lokeshwar N. Febrile neutropenia in haematological malignancies. J Postgrad Med 2005; 51 (Suppl 1): S42-S48.

7. Link H, Bohme A, Cornely OA, Hoffken K, Kellner O, Kern $\mathrm{WV}$, et al. Antimicrobial therapy of unexplained fever in neutropenic patients - guidelines of the Infectious Diseases Working Party (AGIHO) of the German Society of Hematology and Oncology (DGHO), Study Group Interventional Therapy of Unexplained Fever, Arbeitsgemeinschaft Supportivmassnahmen in der Onkologie (ASO) of the Deutsche Krebsgesellschaft (DKG-German Cancer Society). Ann Hematol 2003; 82 (Suppl 2): S105-S117, doi: 10.1007/s00277-003-0764-4.

8. Talcott JA, Siegel RD, Finberg R, Goldman L. Risk assessment in cancer patients with fever and neutropenia: a prospective, two-center validation of a prediction rule.
(37-39). Finally, sTNFRI concentration is easier to measure than TNF- $\alpha$ levels, which makes it a more reliable serum marker (40)

This study showed that plasma sTNFRI levels represent a promising marker to predict the occurrence of fever in onco-hematological patients with neutropenia. A larger study is needed to confirm the role of sTNFRI as a fever predictor in neutropenic patients with hematological diseases.

\section{Acknowledgments}

\section{Research supported by FAPEMIG and CNPq.}

9. Viscoli C, Bruzzi P, Castagnola E, Boni L, Calandra T, Gaya $\mathrm{H}$, et al. Factors associated with bacteraemia in febrile, granulocytopenic cancer patients. The International Antimicrobial Therapy Cooperative Group (IATCG) of the European Organization for Research and Treatment of Cancer (EORTC). Eur J Cancer 1994; 30A: 430-437, doi: 10.1016/0959-8049(94)90412-X.

10. Lucas KG, Brown AE, Armstrong D, Chapman D, Heller G. The identification of febrile, neutropenic children with neoplastic disease at low risk for bacteremia and complications of sepsis. Cancer 1996; 77: 791-798, doi: 10.1002/ (SICI)1097-0142(19960215)77:4<791::AID-CNCR27>3.0.CO; 2-V.

11. Engel A, Mack E, Kern $P$, Kern WV. An analysis of interleukin-8, interleukin-6 and C-reactive protein serum concentrations to predict fever, Gram-negative bacteremia and complicated infection in neutropenic cancer patients Infection 1998; 26: 213-221, doi: 10.1007/BF02962366.

12. Beutler B. Inferences, questions and possibilities in Toll-like receptor signalling. Nature 2004; 430: 257-263, doi: 10.1038/nature02761.

13. Rackoff WR, Gonin R, Robinson C, Kreissman SG, Breitfeld $\mathrm{PB}$. Predicting the risk of bacteremia in childen with fever and neutropenia. J Clin Oncol 1996; 14: 919-924.

14. Houck PM, Bratzler DW, Nsa W, Ma A, Bartlett JG. Timing of antibiotic administration and outcomes for Medicare patients hospitalized with community-acquired pneumonia. Arch Intern Med 2004; 164: 637-644, doi: 10.1001/ archinte.164.6.637.

15. Kumar A, Roberts D, Wood KE, Light B, Parrillo JE, Sharma $S$, et al. Duration of hypotension before initiation of effective antimicrobial therapy is the critical determinant of survival in human septic shock. Crit Care Med 2006; 34: 1589-1596, doi: 10.1097/01.CCM.0000217961.75225.E9.

16. Klastersky J, Paesmans M, Rubenstein EB, Boyer M, Elting L, Feld R, et al. The Multinational Association for Supportive Care in Cancer risk index: A multinational scoring system for identifying low-risk febrile neutropenic cancer patients. $J$ Clin Oncol 2000; 18: 3038-3051.

17. Ugarte H, Silva E, Mercan D, De Mendonca A, Vincent JL. Procalcitonin used as a marker of infection in the intensive care unit. Crit Care Med 1999; 27: 498-504, doi: 10.1097/ 
00003246-199903000-00024

18. Selberg O, Hecker H, Martin M, Klos A, Bautsch W, Kohl J. Discrimination of sepsis and systemic inflammatory response syndrome by determination of circulating plasma concentrations of procalcitonin, protein complement $3 a$, and interleukin-6. Crit Care Med 2000; 28: 2793-2798, doi: 10.1097/00003246-200008000-00019.

19. Muller B, Becker KL, Schachinger H, Rickenbacher PR, Huber PR, Zimmerli W, et al. Calcitonin precursors are reliable markers of sepsis in a medical intensive care unit. Crit Care Med 2000; 28: 977-983, doi: 10.1097/00003246200004000-00011.

20. Aouifi A, Piriou V, Bastien O, Blanc P, Bouvier H, Evans R, et al. Usefulness of procalcitonin for diagnosis of infection in cardiac surgical patients. Crit Care Med 2000; 28: 31713176, doi: 10.1097/00003246-200009000-00008.

21. Marshall JC, Foster D, Vincent JL, Cook DJ, Cohen J, Dellinger RP, et al. Diagnostic and prognostic implications of endotoxemia in critical illness: results of the MEDIC study. J Infect Dis 2004; 190: 527-534, doi: 10.1086/ 422254.

22. O'Grady NP, Barie PS, Bartlett JG, Bleck T, Carroll K, Kalil $A C$, et al. Guidelines for evaluation of new fever in critically ill adult patients: 2008 update from the American College of Critical Care Medicine and the Infectious Diseases Society of America. Crit Care Med 2008; 36: 1330-1349, doi: 10.1097/CCM.0b013e318169eda9.

23. Persson L, Soderquist $B$, Engervall $P$, Vikerfors $T$, Hansson LO, Tidefelt U. Assessment of systemic inflammation markers to differentiate a stable from a deteriorating clinical course in patients with febrile neutropenia. Eur J Haematol 2005; 74: 297-303, doi: 10.1111/j.1600-0609.2004.00387.x.

24. Engervall $P$, Andersson B, Bjorkholm M. Clinical significance of serum cytokine patterns during start of fever in patients with neutropenia. Br J Haematol 1995; 91: 838-845, doi: 10.1111/j.1365-2141.1995.tb05398.x.

25. Engel A, Knoll S, Kern P, Kern WV. Interleukin-8 serum levels at fever onset in patients with neutropenia predict early medical complications. Infection 2005; 33: 380-382, doi: $10.1007 / \mathrm{s} 15010-005-5068-2$.

26. Goetz M, Schiel X, Heussel H, Steinmetz T, Hiddemann W, Weiss M. Elevation of soluble tumor necrosis factor receptor II in non-febrile patients with acute myeloid leukemia. Eur $J$ Med Res 2002; 7: 487-490.

27. Engel A, Steinbach G, Kern P, Kern WV. Diagnostic value of procalcitonin serum levels in neutropenic patients with fever: comparison with interleukin-8. Scand J Infect Dis 1999; 31: 185-189, doi: 10.1080/003655499750006254.

28. Goetz M, Behre G, Heussel G, Steinmetz HT, Eigler A, Hiddemann W, et al. Soluble tumor necrosis factor receptor type II in the early diagnosis of fever in neutropenia. Ann Hematol 2002; 81: 382-385, doi: 10.1007/s00277-0020482-3.

29. Buyukberber N, Buyukberber S, Sevinc A, Camci C Cytokine concentrations are not predictive of bacteremia in febrile neutropenic patients. Med Oncol 2009; 26: 55-61, doi: 10.1007/s12032-008-9081-z.

30. Holler E, Kolb HJ, Moller A, Kempeni J, Liesenfeld S, Pechumer $\mathrm{H}$, et al. Increased serum levels of tumor necrosis factor alpha precede major complications of bone marrow transplantation. Blood 1990; 75: 1011-1016.

31. Rogy MA, Coyle SM, Oldenburg HS, Rock CS, Barie PS, Van Zee KJ, et al. Persistently elevated soluble tumor necrosis factor receptor and interleukin-1 receptor antagonist levels in critically ill patients. J Am Coll Surg 1994; 178: 132-138.

32. Spinas GA, Keller $U$, Brockhaus M. Release of soluble receptors for tumor necrosis factor (TNF) in relation to circulating TNF during experimental endotoxinemia. J Clin Invest 1992; 90: 533-536, doi: 10.1172/JCl115891.

33. Van Zee KJ, Kohno T, Fischer E, Rock CS, Moldawer LL, Lowry SF. Tumor necrosis factor soluble receptors circulate during experimental and clinical inflammation and can protect against excessive tumor necrosis factor alpha in vitro and in vivo. Proc Natl Acad Sci U S A 1992; 89: 48454849, doi: 10.1073/pnas.89.11.4845.

34. Higuchi M, Aggarwal BB. TNF induces internalization of the p60 receptor and shedding of the p80 receptor. J Immunol 1994; 152: 3550-3558.

35. Parillo VL. Systems analysis of an occupational health department: recommendations to increase effectiveness. AAOHN J 1993; 41: 220-227.

36. Bazzoni $F$, Beutler $B$. The tumor necrosis factor ligand and receptor families. N Engl J Med 1996; 334: 1717-1725, doi: 10.1056/NEJM199606273342607.

37. Kern WV, Engel A, Kern P. Soluble tumor necrosis factor receptors in febrile neutropenic cancer patients. Infection 1995; 23: 64-65, doi: 10.1007/BF01710064.

38. Tracey KJ, Cerami A. Tumor necrosis factor: a pleiotropic cytokine and therapeutic target. Annu Rev Med 1994; 45: 491-503, doi: 10.1146/annurev.med.45.1.491.

39. Aderka D, Engelmann H, Shemer-Avni Y, Hornik V, Galil A, Sarov B, et al. Variation in serum levels of the soluble TNF receptors among healthy individuals. Lymphokine Cytokine Res 1992; 11: 157-159.

40. Gelape CL, Sanches MD, Teixeira AL, Teixeira MM, Braulio $\mathrm{R}$, Pinto IF, et al. Preoperative plasma levels of soluble tumor necrosis factor receptor type I (sTNF-RI) predicts adverse events in cardiac surgery. Cytokine 2007; 38: 9095, doi: 10.1016/j.cyto.2007.05.007. 